\title{
Feeling able to say it like it is: a case for using focus groups in programme evaluation with international cohorts
}

\section{Article}

Accepted Version

Creative Commons: Attribution-Noncommercial-No Derivative Works 4.0

Marra, M. and McCullagh, C. (2018) Feeling able to say it like it is: a case for using focus groups in programme evaluation with international cohorts. International Journal of Management Education, 16 (1). pp. 63-79. ISSN 1472-8117 doi: https://doi.org/10.1016/j.ijme.2017.12.006 Available at https://centaur.reading.ac.uk/74411/

It is advisable to refer to the publisher's version if you intend to cite from the work. See Guidance on citing.

To link to this article DOI: http://dx.doi.org/10.1016/j.ijme.2017.12.006

Publisher: Elsevier

All outputs in CentAUR are protected by Intellectual Property Rights law, including copyright law. Copyright and IPR is retained by the creators or other copyright holders. Terms and conditions for use of this material are defined in the End User Agreement.

www.reading.ac.uk/centaur

\section{CentAUR}


Central Archive at the University of Reading

Reading's research outputs online 


\title{
Feeling able to say it like it is:
}

\section{A case for using focus groups in programme evaluation with international cohorts}

\author{
Miriam Marra $^{\mathrm{a}}$ \\ ICMA Centre - Henley Business School \\ University Of Reading
}

\author{
Clare McCullagh ${ }^{\mathrm{b}}$ \\ Centre for Quality Support and Development \\ University of Reading
}

\begin{abstract}
In today's cost- and efficiency-conscious environment there may be resistance amongst HEIs to use informal verbal approaches to programme evaluation, such as focus groups, due to their resource-intensive nature. There may also be a lack of confidence amongst staff working with international cohorts about having the necessary skills to facilitate evaluative discussion and create an atmosphere of trust and openness. Drawing directly from three years' experience of directing a Finance programme with an international cohort of four to ten students in a UK University, this paper argues that focus groups offer an invaluable source of rich feedback. As the HE sector prepares for the TEF, and Business, Management and Finance dealing programmes continue to rely on high numbers of international students, this is an opportune time for programme directors to reflect on how their commitment to teaching excellence is evidenced beyond rhetoric and box-ticking. The value of making space for the student voice is not limited to T\&L enhancement, but includes:

- helping students to develop reflective and critical thinking

- enabling them to negotiate programme changes

- engaging students with issues concerning their learning experience

- ensuring that diversity and inclusion are central to discussion agendas

- forging HEI-students partnership in the learning process.
\end{abstract}

Keywords: Verbal feedback; Focus groups; Programme evaluation; Internationalisation; Students as partners in $\mathrm{T} \& \mathrm{~L}$; Intercultural communication.

\footnotetext{
${ }^{a}$ Corresponding Author - Email: m.marra@icmacentre.ac.uk ; Address: ICMA Centre, Henley Business School, University of Reading, Whiteknights Campus, RG6 6BA, UK. Phone: +44 (0) 1183786924.

${ }^{\mathrm{b}}$ Email: c.e.mccullagh@reading.ac.uk; Address: Centre for Quality Support and Development, University of Reading, Whiteknight House, Whiteknights Campus, RG6 6AH, UK. Phone: +44 (0) 1183784482.
} 


\section{Introduction}

This paper explores and promotes the use of focus groups for collecting student feedback on teaching \& learning at the Programme level. The University concerned is a research intensive institution and enjoys a world-class reputation for its Business and Management programmes. The specific context concerned is the review processes for the MSc in Investment Banking and Islamic Finance with an international cohort of four to ten students.

The specific theme of focus groups meets three core objectives for Higher Education Institutions (HEIs) in gathering students' evaluation data, as defined by David (2013): 1) improving the quality of teaching; 2) enhancing the students' experience; and 3) providing information for decisionmakers. As David (2013) highlights, student evaluation and feedback processes are no longer considered by HEIs as a 'tick-box' exercise for institutional quality assurance; universities are now encouraging varied and innovative mechanisms to drive forward enhancement and to allow for comparison at an institutional level.

The paper also considers an additional objective for collecting student feedback, which is promoting a dialogue within HEIs and building "a genuine partnership between teachers and students" (David, 2013). The concept of partnership is at the centre of this paper focusing on how to improve feedback collection, interpretation and application at the MSc programme-level within a business and management context.

The context for the work described in this paper is significant for two reasons. Firstly, during a time when HE management approaches are increasingly relying on metrics and there is nervous anticipation in relation to the impact of the TEF, it is timely to ensure real voices are listened to and heard. Secondly, as student fees increase and HEIs strive to meet the needs of increasingly diverse groups of students on business and management programmes, with growing international cohorts, HEIs need to be fully informed in order to meet high student expectations, to provide them with the best possible experience and value for money.

The paper is structured as follows. Section 2 provides a brief clarification on the nature of focus groups in social science research. Section 3 presents an outline of the specific institutional context in which the evaluation approaches based on focus groups have been developed and considers some of the benefits and challenges of collecting verbal feedback. Section 4 reviews relevant literature including the Realist Evaluation theory (Pawson \& Tilley, 1997), which underpins the approach advocated here. Section 5 considers the use of verbal feedback processes more specifically within international cohorts. Section 6 presents the outcomes from our experiences with focus groups to date, leading to a proposed plan of action to enhance future evaluation processes. Finally, in Section 7 , some concluding remarks are presented. 


\section{What is a Focus Group?}

This section briefly clarifies the general characteristics, advantages, and disadvantages of focus groups for research in social sciences and, more specifically, in education.

Focus groups are used to elicit opinions, feedback, suggestions, and foster an understanding of how a specific group of people think and feel about a certain topic or experience. A focus group is a "technique involving the use of in-depth group interviews in which participants are selected because they are a purposive, although not necessarily representative, sampling of a specific population, this group being 'focused' on a given topic" (Thomas, MacMillan, McColl, Hale, \& Bond, 1995).

There are many ways to organize a focus group. First, there is no 'magic number' of participants; however, a relatively smaller size helps to foster the discussion in a more intimate way. Second, the focus group is generally group-led, with the help of one or more facilitators or interviewers. Third, it can be run face-to-face or online and it normally consists of open-ended questions which aim to achieve higher reflective thinking, deeper discussion and higher confidentiality.

Amongst the advantages of using focus groups, Cohen, Manion, and Morrison (2007) point out that "the participants interact with each other rather than with the interviewer, such that the views of the participants can emerge - the participants' rather than the researcher's agenda can predominate". Focus groups can also help to develop collective identity (Munday, 2006). In addition, they represent more informal, relaxed way of conducting an interview that feels more like a conversation where "participants are explicitly encouraged to talk to one another, as opposed to answering questions of each person in turn" (May, 2011).

The "contrived nature" of focus groups is "both their strength and their weakness: they are unnatural settings yet they are very focussed on a particular issue and, therefore, will yield insights that might not otherwise have been available" (Cohen et al. 2007). The management and facilitation of focus groups can be challenging. It is not easy to understand how to capture a lot of discussion in a short space of time and to ensure that all participants discuss their views, also those with less dominating personalities. Goldfarb and Morrison (2014) identify as other potential barriers "the time and resource intensive nature of the model" and "the need of skilful purveyors of feedback".

Several more advantages and disadvantages will be highlighted in this paper at sections 3 and 6 , as they emerged from this specific experience of focus groups to collect students' verbal feedback for the evaluation of a MSc programme. 


\section{The Need for Verbal Feedback in HEI Evaluation of Programmes}

This section outlines the broader HE and institutional context in which the demand and need for verbal feedback has developed in recent years and addresses some of the benefits and challenges of such approaches to evaluation.

The UK government's White Paper (2011) response to the Browne Review (2010), appropriately entitled "Higher Education: Students at the Heart of the System", set out proposals in response to the new Student Finance Plan through which students are now the main funders of higher education in the UK. The aim is to improve the student experience by offering high-quality teaching, assessment and feedback. The latter "will take on a new importance to empower students whilst at University." Under this general guideline more specific provisions are offered in the same document, particularly in Chapter 3 ("A better student experience and better qualified graduates"). Besides well-established formal practices like surveys for student evaluations of teaching, the document seeks HEIs' involvement in informal feedback on the students' learning experience. It also poses great emphasis on the need of publishing and disseminating the information obtained by the feedback. The report aimed to make universities more accountable than ever before. Greater 'accountability' is now encouraged through the introduction of the National Student Survey since 2005, the International Student Barometer (ISB) also since 2005, the Postgraduate Taught Experience Survey (PTES) since 2009 and, controversially, through the publication of university league tables.

The UK Quality Code for HE published in 2012 introduced the terminology of 'partnership' used to indicate a mature relationship between students and staff based on values of openness, trust, honesty, agreed shared goals and values, and regular communication between the partners "in informal and formal arrangements." The Higher Education Academy (HEA) in the UK has produced a number of documents that reinforce the Quality Code's concept of students as partners ${ }^{1}$ in all aspects of HE; including feedback and evaluation for quality enhancement of HEIs.

The increase in student fees has resulted in further shifts, most notably, in student perceptions and expectations, with universities now finding themselves "under increased pressure to adopt a more customer-focused approach" (Snowden, 2013). HEIs in England are increasingly operating under forces of marketization which demand competitiveness, efficiency and consumer satisfaction (Lesnik-Oberstein, 2015). This consumer identity appears to be increasingly recognised also by students who demand and expect more from the higher education sector (Kandiko \& Mawer, 2013; Tomlinson, 2014, 2017). While the business world increasingly relies on customer feedback to help organisations understand customer needs and concerns and improve the value and efficiency of their services, the HE sector is less comfortable in adopting business-oriented approaches. Academics in particular challenge this model and highlight the risks of considering students as 'customers' or 'end-users', not only in terms of heightened expectations. An analysis by Bunce, Baird, and Jones (2016) reveals in fact that a higher consumer orientation is associated with lower academic performance.

The elevation of students to the status of customers might however imply that the 'student voice' is currently receiving greater attention in recent years than previously. This paper argues that space needs to be created for the individual voice to be heard. This is in part due to the increasing diversity of both staff and student cohorts. Differences across educational systems and, therefore, differences in expectations, need to be taken into account when one considers the different educational cultures

\footnotetext{
${ }^{1}$ Some of these documents can be accessed at: http://www.heacademy.ac.uk/students-as-partners.
} 
of international students who represent the largest component in the MSc programmes offered by the Business School within the context of this paper, as well as the culture of the person who collects the feedback (the facilitator) and/or interprets them (the evaluator).

A further reason to create space for more informal and personal approaches to evaluation relates to the pressures academic staff face in their day to day roles. Colleagues within institutions face many challenges in their roles which are acknowledged to be stressful: increasing staff-student ratios, recent 'streamlining' of administrative support, and pressure to win funding and to publish. It is acknowledged in the literature that such pressures might have "reduced the time available for informal face-to-face meetings between staff and students. All of these trends have led to the gradual replacement of the informal with the formal, of which the widespread introduction of student feedback surveys has been a conspicuous part" (Brennan \& Williams, 2004). Focus groups can represent a challenge to traditional views but, where a dialogue takes place between participants, they can also help to build bridges between staff and students and to create a stronger sense of belonging and understanding for those less familiar with the UK HE environment.

Other challenges have emerged from increasing demands for 'accountability' within the HE sector, and the consequent urge to publish information about service standards and performance indicators in league table format. On the one hand, increasingly standardized quality assurance policies can result in a loss of human and personal contact between teachers and students which might undermine a feedback process ideally based on trust and partnership. On the other hand, individual staff-led initiatives to collect feedback, while maximizing commitment and enthusiasm towards building a partnership with students, can be hampered by lack of understanding/comparability of criteria across and within institutions.

King, Morison, Reed, and Stachow (1999) explain that some degree of institutional centralized support for student feedback is desirable: for instance, the institution can effectively convey its message to all staff members that student opinion is valued and taken seriously. Moreover, since the verbal feedback process can be very resource-intensive for facilitators, evaluators, and students, the institutional-led approach can provide precious administrative support. Clearly, there is a need to strike a balance. A reliance upon formal, systemised approaches alone may come across to students as impersonal. Meanwhile, centralised approaches and online survey automation software (e.g. EvaSys), remind staff of performance management and managerialism which can undermine staff confidence.

In many HEIs, particularly in the US and UK, the most common methodology for collecting student feedback is the module evaluation questionnaire (MEQ). Despite the clear advantages of this methodology (anonymity, standardization, time-efficiency, comparability, and the potential to collect large numbers of responses), there are inevitably aspects which are not easily captured by MEQs alone, and, as a consequence, might be ignored due to limitations in the survey's scope and in the level of students' engagement. For example, many students may suffer from 'questionnaire fatigue' so their response rates may be low, and others are happy to tick a box, but may not complete the open-ended comments sections which tend to provide the rich qualitative explanations and elaborations (Adams \& Umbach, 2011).

Written surveys therefore need to be complemented by more informal ways of collecting evaluations verbally which allows for the richness of student voices to be heard. This recognition is not new; in the past Gibbs, Habershaw, and Habershaw (1989); Hounsell, Tait, and Day (1997); and Day, Grant, 
and Hounsell (1998) and others have all called for broader and more bespoke approaches to collecting student feedback to allow for different programme contexts and ethnicities.

The institution considered in this study makes mandatory use of MEQs for all modules within undergraduate and postgraduate programmes and a template is provided for all staff to use. The template provides a set format which ensures standard questions are asked across the institution, within which Module Convenors are able to add their own tailored, context specific questions. Some form of programme evaluation is compulsory for all programmes on an annual basis, but Programme Directors are encouraged to be creative in their approaches to evaluation at the level of the programme, and are given free rein to choose their own feedback methods, including discussion, focus groups and informal dialogue. This approach in part draws on the success of an institutional initiative to incorporate focus groups within the institution's Periodic Review process. In response to this encouragement many Programme Directors at the institution have organized some forms of focus groups. For the MSc programme in Investment Banking and Islamic Finance (the pilot 'experiment' in this context), a first focus group was held in May 2013.

Beyond the level of the module, programme evaluation provides a sense of how effectively different programme elements are threaded together, and what the 'overall' experience is for students. Programme evaluation moves beyond the focus on individual modules, teaching teams and individual lectures to consider programme structure, purpose and outcomes: to focus "on the script as well as on the actors" (Biggs, 2001). Hounsell (2009) points out that "aggregating module feedback does not convert it into feedback on the student experience of the programme as a whole" and highlights the suitability of focus groups for this purpose, in particular in offering "more informal and relatively open-ended ways of pooling thoughts and reactions".

While evaluations and questionnaires are used by many HEIs for summative purposes, such as to compare teaching performance of individuals or to compare module scores across programmes, the evaluation process should always be carried out for formative and developmental purposes: that is, the overall aim should be quality enhancement (D'Andrea \& Gosling, 2005).

\section{Realist Evaluation and Feedback Focus Groups}

One theory which supports verbal feedback approaches and helps to train facilitators/evaluators for their multiple tasks, i.e. collecting opinions, interpreting the results, and taking action, is the socalled realist evaluation. The term 'realist evaluation' is taken from Pawson and Tilley's (1997) seminal work "Realistic Evaluation". The realist evaluation is grounded in realism 'Realism' is a school of philosophy which asserts that both the material and the social worlds are 'real' and can have real effects; and that it is possible to work towards a closer understanding of what causes change. The realist evaluation explains how the evaluator should engage with the 'stakeholders', who are all the individuals involved in the process of evaluation of a programme and benefiting from any action resulting from it. In this specific case, where the object of evaluation is a postgraduate programme of a HEI, the main stakeholders are the current students, but other stakeholders include departments within the institution, for example the marketing, quality assurance, and admission departments, the programme teaching and management team and the future students. Realist evaluation sees the stakeholders as key sources for "providing data on how the programme works. But it is not assumed that they are all-knowing, nor that they will necessarily agree on how, for 
whom and in what circumstances a programme will work. Stakeholders generally have experience of and thus expertise in particular phases and process within an intervention. (...) Stakeholders are treated as fallible experts whose understanding needs to be formalised and tested" (Pawson \& Tilley, 2004).

There are two main reasons why this theory can be well suited to an evaluation process where students are the main stakeholders. On the one hand, students are the richest source of information: they attend the modules, are assessed in exams, interact with lecturers, access learning resources, and interact with the programme at many levels. However, some students may be unprepared to reflect critically on their learning experience. Some of their aims may be short-term. A teacher or HE evaluator is more likely to see the bigger picture and understand the pedagogic rational behind the teaching methodologies. For example, students often request a lot of mock tests and exams to train for their final assessment; a teacher may see in this request a risk that the learning methodology of students and in particular their approach to exams can become too instrumental, rather than encompassing all different aspects of their learning experience which are useful also in their lives beyond exams.

The realist evaluation theory reminds the evaluator that programmes "cannot be fully isolated or kept constant. Unanticipated events (...) make programmes permeable and plastic. Such externalities always impact on the delivery of a programme and this entails that they are never quite implemented in the same way" (Pawson \& Tilley, 2004). Possible changes in future scenarios can modify the outcome of the evaluation and also the actions to be taken: for example, changes of lecturers, Programme Director, University policies, partnerships with other HEIs, student composition, etc. All these situations require the evaluator to adopt a 'contingent' realist approach. The realist evaluator 'asks not, 'What works?' or 'Does this program work?' but asks instead, 'What works for whom in what circumstances and in what respects, and how?" (Pawson \& Tilley, 2004). The realist approach suggests therefore awareness and moderation in interpreting the results of programme evaluation and pushes the evaluator to adapt the methodologies for collecting and interpreting feedback to the changing environment. In this sense, the realist evaluation approach can also help to ease the 'emotional' debate within HEIs, as it suggests looking at students as 'stakeholders', rather than mere 'customers', whose engagement is essential for the quality-enhancement processes, but whose opinions are not always infallible.

In addition to Pawson and Tilley's realist evaluation, another helpful framework for evaluation of teaching practice is offered by Brookfield (1995). He explains that in order to become a critically reflective practitioner in all different aspects of $\mathrm{T} \& \mathrm{~L}$, including collection and use of student feedback, a facilitator/evaluator should 'wear' four different lenses: 1) their own autobiography as learner and teacher; ii) their students' eyes; ii) their colleagues' experiences; and iii) the theoretical literature. When collecting feedback, teachers should recall their experience as students, so to become "viscerally connected" with their own students. Through personal self-reflection, teachers should become more aware of the paradigms, assumptions and reasoning behind their actions. "When they know what these are, they can start to test their accuracy and validity through conversations with students" (Brookfield, 1995). Looking at students' experience through students' eyes, engaging in critical conversations with the colleagues, and grounding self-reflection within the theoretical literature make teachers better reflective practitioners. 


\section{The Voice of International Business Students}

The University considered in this study, and, in particular, its Business School, has a majority of international Postgraduate students from different cultural backgrounds and communication styles. This section reviews some theories on verbal communication strategies that should be considered by members of staff when collecting feedback from international students via group discussions. Discussions in focus groups can be a useful tool to develop 'inclusivity' within a classroom or a programme, to provide international students with a 'toolkit' to negotiate and to engage with other students and members of staff on issues that matter for them. Amongst others, De Vita and Case (2003), Koutsantoni (2006), Caruana and Oakey (2004), and Phipps and Gonzalez (2004) have demonstrated that internationisation is an opportunity to develop inclusivity. However, a number of obstacles can preclude the facilitator/evaluator from conducting an effective group discussion with international students.

First, as also explained by Carroll (2005), although international students have been officially admitted by the University and considered competent to undertake studies in English, many of them may not be confident in all aspects of the language and some are limited in their participation by the fear of making language mistakes in the presence of home students or members of staff. Robertson, Line, Jones, and Thomas (2000) suggest that lecturers take responsibility and assist overseas students by speaking especially clearly. The same suggestions apply to the facilitator in a discussion groups with a large number of international students.

Second, besides linguistic reasons, the apparently passive attitude of some international students in the classroom and in focus groups can be caused by differences in their cultural and educational background (Jones, 1999). This is true in particular for students coming from Asian countries, who represent the majority of international students in the UK and in the institution observed in this study. For example, Asian students are typically not inclined to challenge the teacher's authority (Chen, 1987; Romaine, 1986; Chang, 2001). This may cause misunderstandings and even, at times, discrimination. Furneaux, Locke, Robinson, and Tonkyn (1991) studied international students' participation in seminars and observe that international students tend to be "too intent on listening and note-taking and also too dependent on the lecturer for information". Braddock, Roberts, Zheng, and Guzman (1995) undertook a similar survey on international students in Australia. They observed that silence, avoidance of argument or apparently excessive deference to a teacher might be unfavourably evaluated by a native Western teacher. MacKinnon and Manathunga (2003) and Marlina (2009) find that academics consider silence in the classroom as negative and lack awareness that silence could be a sign of respect and a key aspect of the thought process. Such negative perceptions need to be challenged. Jones (1999) suggests helping international students to become more active participants in discussion groups by explaining to students "the ethos of the tutorial or seminar in a Western English-speaking country" and developing "their interactional skills and command of the discourse norms that they will need in order to become equal partners with NS [national] students."

Verbal feedback shares many of the attributes of informal conversations, such as the use of colloquial language. For example, teachers and discussion-group facilitators often ask to be called by their first names, invite interruptions, and in general encourage free participation. Formality instead prescribes "fixed interactional routines" (Fairclough, 1989), which would conflict with a concept of conversation characterized by partnership and solidarity and a close relationship between speakers and listeners (Brown \& Levinson, 1987). However, in order to achieve partnership and solidarity, 
one first has to achieve a greater cultural understanding. Academics who support international students need to be appropriately trained regarding cross-cultural awareness. The institution in this study, like many others, now offers staff development workshops to address intercultural awareness and understanding, which is a helpful development.

There is a variety of communication styles that the facilitator/evaluator may encounter in informal discussions with international students during focus groups, as outlined by Neuling (1999), and different verbal communication styles depend on the type of culture students come from. The styles are summarized in Table 1 in Appendix I. Differences in communication styles between different cultures reinforce the importance for facilitators/evaluators to receive training in order to: i) recognize different language patterns and behaviours of students in informal conversation; and ii) respond to issues of multiculturalism within the verbal feedback process. In other words, facilitators need to be interculturally aware.

\section{The Experience of Focus Groups with Students of MSc in Investment Banking and Islamic Finance in the Business School at the University}

After discussing the policy changes in UK HEIs that call for a more active engagement of students as partners in T\&L, the benefits and challenges of feedback focus groups at the programme level, and the issues related to multiculturalism and differences in communications styles; this section presents an experience with focus groups in a Business School context.

First, it clarifies the main characteristics of the Postgraduate programme which is the object of students' evaluation in this project: the MSc in Investment Banking and Islamic Finance.

\subsection{MSc in Investment Banking and Islamic Finance}

The MSc Investment Banking and Islamic Finance (hereafter MSc IBIF) is one of the programmes included in the portfolio of Postgraduate Finance Masters offered in the Department of Finance in the Business School considered in this project.

The aim of the programme is to prepare graduates for a career in the international investment banking industry in positions in which they might wish to demonstrate knowledge of both conventional ("Western") and modern Islamic approaches to finance. This degree does not require any previous knowledge of Islamic Law or concepts and addresses the specific issues of Islamic finance within a secular, Western-oriented context.

The programme involves a partnership between the UK institution and a HE institution specializing in Islamic Finance in Malaysia. Students can follow two routes in the programme. Besides those enrolled in the MSc IBIF 12-months programme who attend modules in the UK and in Malaysia, a 9-month MSc IBIF programme is also offered, where students can opt out from spending the additional weeks in Malaysia and replace those credits with elective module/s in the UK. Upon completion of MSc IBIF the students qualify also for an Islamic Finance Professional Certificate awarded by the partner institution.

The partnership between the two Universities to provide higher education services in the field of Islamic Finance started in May 2008. Over the years, from 2008 to 2015, the total number of 
students enrolled in the MSc IBIF has varied, but it has always stayed as small as four to ten (including both 9- and 12-month students). In the four academic years covered by this focus group experiment, there were: ten students in 2012/13, ten students in 2013/14, eight in 2014/15, and four in 2015/16. Islamic Finance is still a niche discipline in Finance; therefore, it attracts targeted students, in particular coming from countries with a Muslim majority mostly from the Middle-East and Africa.

\subsection{The Feedback Cycle}

Six steps were followed to collect, interpret, disseminate students' feedback, and take action. These steps constitute the 'feedback cycle'.

Step 1: Clarify the purposes of the feedback to self (facilitator/evaluator) and to students, before starting the procedure;

Step 2: Select the feedback methodology, timing, and questions to be asked;

Step 3: Collect the feedback via informal discussion;

Step 4: Report the results in a document; disseminate it to the Programme Committee and other stakeholders, including students; collect comments and revise the document;

Step 5: Reflect critically on the outcome and take action, where appropriate;

Step 6: Feed-back to students the outcome of the procedure, i.e. close the feedback loop.

The following paragraphs describe each step and discuss this experience, reporting also some evidence collected from the focus groups. ${ }^{2}$

\subsubsection{Purpose of Feedback}

It is fundamental to clarify the purposes of collecting feedback at the programme level before starting, as this motivates the evaluator, the students, and the institution to support the process. As suggested by Brennan and Williams (2004), the main purpose is to enable a dialogue with students; help students reflect upon their experiences as part of the T\&L process; identify good practice; measure student satisfaction; and contribute to staff development. In addition, the feedback focus group can be useful when a programme is relatively new, when it involves an external partnership, and/or when changes have been introduced in its structure. Since the Business School intends to develop other new programmes with external partnerships, the experience of focus groups for the relatively new MSc IBIF can help also with those. This approach is perfectly consistent with a realist evaluation approach explained in section 4.

During the academic years 2012/13, 2013/14, and 2014/15 four 'structured' focus groups were conducted. In October 2013 a long meeting with MSc IBIF students was also used to collect 'incidental' feedback. In May 2013 the first end-of-programme focus group was held. This focus group was run by the MSc Programme Director (PD) and one more facilitator (the Director of Administration \& Student Affairs) and it revealed several issues related to the programme structure and the organization of students' visit at the partner institution in Kuala Lumpur. Having stepped in the role just two months before this focus group, this feedback helped the PD to identify the areas of

\footnotetext{
${ }^{2}$ We have received explicit ethical consent from the 2014/15 students' cohort and the 2013/14 12-months cohort. All evidence is anonymized.
} 
improvement for the coming years. As students' dissatisfaction was mainly caused by motives which were not related to the taught component of the modules, this feedback could not have been collected using MEQs only: a programme-level discussion was necessary. The collection of feedback via a focus-group was a 'rich' methodology to understand the nature, problems, and priorities of the PD job (clarification of purposes to 'self').

\subsubsection{Choice of Questions to be asked}

The PD drew on a set of core questions for each focus group. However, as evidenced in Appendix II, additional questions vary depending on where in the programme timeline the focus group occurred. For example, questions were tailored according to whether the students were asked at the end of the programme or in the middle, and on whether the 'surveyed' students were in the 12-month programme or in the 9-month one or in both. Examples of questions are provided in Appendix II.

The scope of the questions, the methodologies of the focus groups and the timings have changed since the first focus group in May 2013. Some of these changes are in response to advice in the literature. For example, in the focus group in February 2015 a wider range of questions were asked and, following the suggestions of Brennan and Williams (2004), more questions were added on the overall teaching quality, the variety of teaching methods, the pastoral care and guidance from teaching staff and the availability and accessibility of resources (see evidence in Appendix II: questions 3, 4, and 5). This is the widest and most comprehensive set of questions used in the focus groups run, which is why it is reported as evidence in the Appendix II of this paper. This example also demonstrates the benefits of engaging with scholarly literature on evaluation. In this specific context, familiarisation with the literature has also helped to develop the PD's confidence in trialling new approaches beyond the standard MEQs.

The focus group for the 12-month students in July 2014 was run via an online visual communications software (e.g. Skype), as an attempt to collect students' feedback on their experience in Malaysia in 'real time'. The meeting was set at a time when students had already completed all their modules, but not yet sat their exams. As evidenced in Appendix II, the focus group was successful in collecting rich information. We choose to report this focus group questions to show how much information was collected in spite of the virtual technical setting.

\subsubsection{Choice of Timing}

From this focus-group experience, it can be noted that the most useful timings to collect feedback at the programme-level are mid-year, after Term 1 exams and during Term 2, or the end of the year, after Term 2 exams. In fact:

I) Collecting incidental or informal feedback on the programme structure at the beginning of the academic year, in October and November, can be too early. Students are not well-informed about the overall structure of the programme and not completely settled. A valid example can be drawn from the incidental verbal feedback collected from MSc IBIF students in October 2014. From that meeting it became clear that students were not particularly satisfied with the amount of Islamic Finance credits taught in the programme which prompted discussion about further developing this aspect of the programme. However, most of the Islamic Finance modules are compulsory only in Term 2. In Term 1, students are mostly attending modules of conventional finance: that could have biased their judgement on the overall structure of the programme. It is possible, therefore, that the timing of the feedback and the follow-up actions requested were inconsistent with the students' experience in the programme. The fallibility of their opinion as 'stakeholders' was not critically 
evaluated (see: realist approach), as it should have been. As a consequence, in the academic year 2014/15 the first feedback was elicited only in February. By this time students had completed the first module of Islamic Finance, they had been assessed with exams and coursework (group projects and individual essays), and had already attended three weeks of Islamic Finance modules. As expected, the complaint about the paucity of Islamic Finance modules did not appear in the responses of the July 2014 and February 2015 focus groups (see Appendix II).

II) As explained by Hounsell (2009), there are a number of problems associated with end-of-year feedback. ${ }^{3}$ This is also why a mid-year focus group was trialled in February 2015. In this period, students are relatively less occupied with preparation and exam revision. Moreover, they can appreciate that their feedback will be used to enhance their own learning experience, as opposed to only future students' learning experience. The timing of the feedback should be crucially connected with the possibility of an "action" following it. Smith and Morris (2011) point out that "ideally students want the opportunity to express their views on course improvements at a time that their feedback benefits them directly." Obviously, this choice carries some risks. The "evaluator" should always take into his/her own account: i) whether it is viable to act on the feedback on time to provide an improvement for current students; and ii) how to avoid students' disappointment. It is very important that an evaluator is clear with students about what and how much can be done when the feedback loop is closed (see: realist approach).

\subsubsection{Choice of Methodology}

From this experience of feedback process it was noted that a verbal discussion with students helps to create a sense of 'trust' by means of a personal contact and knowledge of the interlocutor. The group discussion need not be a 'physical one', it can also be held in other ways, when and if necessary, e.g. via an online visual communications software, as in the July 2014 focus group. These informal discussions work well when the facilitator/evaluator is a person 'close' to the students, and not only a teacher who taught and assessed the students in a specific module. In this case, the facilitator was also the Programme Director and Personal Tutor for all of the students involved in the focus group. The closeness of the existing relationship helped students to open up on several topics.

Nevertheless, if the facilitator is a member of the teaching staff, he/she always needs to reassure students about his/her role of facilitator in the discussion and should try to lower the 'powerdistance' (Hofstede, 1997). To this purpose, a number of strategies can be followed: for instance, coffee and biscuits should be provided for students who participate with the intention of creating a friendly free-speech space were students can feel as if they are simply 'chatting over a coffee'. This was done for the focus group in February 2015.

Importantly, participation in these focus groups has always been voluntary. Contrarily to Brandl, Mandel, and Winegarden (2017) who think that voluntary participation may lead to a sample selection bias, the approach of Wilson, Morreale, Waineo, and Balon (2015) has been followed in this study in reasonably assuming that student participation is not biased by extraneous factors. As in their experiment, the focus groups were also typically attended by more than half of the students'

\footnotetext{
${ }^{3}$ Hounsell (2009) notes that "waiting until the end of a course before canvassing student opinion, usually on the grounds that the students need to have experienced the whole course before they can effectively comment on it" can have some negative consequences. For example, "the students often find it difficult to recall with much precision a series of practical classes, say, or coursework assignment that took place several months previously. A second consequence is that none of the issues or concerns that students raise will be addressed in time for them to derive any benefit - a situation which is not conducive to good teaching and likely undermine students 'interest in providing worthwhile feedback".
} 
cohort. Although it is conceivable that those who were less positive about the programme would be less likely to participate, equally, they may have attended to express their dissatisfaction. The experience described in this study has evidenced that students' opinions on different aspects of the programmes were a mixture of positive and negative. The discussion did not feel like or appear to result in a biased evaluation, although a larger participation could have further helped to detect any bias.

To further stress the voluntary nature of the verbal feedback, students should be encouraged to set-up the meeting 'together' in collaboration with the facilitator: they can be asked to decide the timing that best suits them, so that the meeting does not appear to be imposed by the teacher and their response can be seen as a sign of their real interest. Finally, the invitation emails should include reassurance that the focus group aims to be a space in which students should feel relaxed and confident to speak openly. In this experiment, the PD has included sentences like: "If you have personal matters you wish to discuss with me, please let me know privately in a separate email and I will book in an appointment for you." Moreover, in order to encourage students to feel as confident as possible the PD started the focus groups by re-stating that she was acting as a facilitator of their discussion and in her role as Programme Director, not as their lecturer. She also invited them to be as open and frank as possible, explaining that it could work to their advantage and help to enhance their learning experience. It is important to explicitly link the focus groups to enhancement of the student learning experience.

All focus groups, and particularly in the one in February 2015, have shown that being friendly and close to students and reassuring them, without crossing the boundaries of the staff-student relationship, is essential to run informal discussion groups, in particular if the discussion is focused also on an appraisal of the T\&L experience and, therefore, of the facilitator and others' work.

\subsubsection{Collect the Feedback}

The end-of-year focus group with the 12-months students in May 2013 lasted one hour. The PD together with one more facilitator asked questions to three participants. The total number of students enrolled in the programme that year was 10, so the participation to the focus group was $30 \%$. Students were asked questions that they had not seen beforehand, which led to repetition in their comments, e.g. in a question on the overall programme structure students discussed a lot the assessment methodologies which were instead the topic of another question. It was observed that students often tend to focus on: $i$ ) the topics that matter most to their performance (marks, exams, and coursework's feedback); and ii) the topics which are closest in time to their experience, e.g. students who were in the process of organizing their trip to Malaysia lamented the lack of organization. Overall the May 2013 focus group worked well as an approach, but it also highlighted the need for more structure and also for directing the discussion towards a more holistic evaluation of the programme as a 'whole'.

In the end-of-year focus group organized for the 9-months students in May 2014 two students participated out of four, so $50 \%$ of the class. This focus group was organized in a similar fashion as the first one in May 2013. Students were asked the questions and given time to think about them and answer them. The main differences between the first experience and this second one were that this focus group was organized and run by the PD alone and that prior to the meeting students were not informed that verbal feedback would be collected. Since students came unprepared, they were given more time to reflect on the issues they had faced during their experience in the programme. During 
this focus group, the PD experienced a greater sense of closeness probably due to the more 'incidental' nature.

Over time, it is clear that a greater sense of closeness and openness has been achieved in the focus groups, which is in part a response to the informal setting provided. There is clearly a delicate balance to be struck between providing 'structure' and 'spontaneity' when organising focus groups.

The programme team have also trialled the use of online focus groups. The focus group for the 12month students in July 2014 was run via an online visual communications software. All five students enrolled in this programme participated. However, this focus group required more organization: several instruction emails were sent to the students to clarify the time-differences between UK and Malaysia and to confirm their attendance. For the first time, students were sent all questions in advance some hours before the meeting in order to understand the topics correctly and reflect on their responses. Besides being more resource-intensive, the online meeting also required more structure in the way it was run: students were divided between two computers. To gather students' responses to the questions talking-rounds were organized. Each student was given a turn to talk, so that he/she could be able to express his/her opinion before handing over to the next student. Technical nuisance was kept to a minimum and the focus group retained the usual atmosphere of solidarity, informality and closeness, despite the geographical distance.

The mid-year focus group in February 2015 was attended by all eight MSc IBIF students. It was the most useful for two reasons. First of all, the rich experience accumulated over the previous two years allowed the PD to be more confident, prepared and well-organized. Second, greater knowledge of the literature on evaluation, communication, and international student engagement had better prepared the PD. In addition, students were given the questions one day in advance. They had taken notes in advance of the meeting on all important points they intended to discuss. However, the need to keep the meeting short was highlighted a few days before by a past student who sent an email with a 'feedback on the feedback process' elicited by the facilitator in preparation for the new focus group. He wrote: "On the disadvantages side, focus groups might be about an hour in length. Busy students will not be able to commit for that time." The meeting lasted exactly one hour with greater consideration of students' busy time. In addition, as mentioned earlier, a greater consideration was given to set up the 'discussion space': coffee and biscuits were offered to the students to create a more welcoming atmosphere.

In this mid-year focus group the number of participating students was higher; this created a challenge in ensuring equal participation to all and minimising the risk of the most outspoken students dominating the discussion. Thus, the discussion was organized in rounds, inverting the order of the round at each question and waiting for an answer from each student before allowing the discussion to then flow more naturally. This has maximized the participation, but slowed down the discussion. This experience has shown that the number of questions needs to be appropriate for the scheduled duration. Nevertheless, the discussion was engaging and successful. It was observed that in this particular stage of the MSc programme (February) students can be very engaged and open: they do not shy away from confrontation, probably because they have developed confidence. They have bonded with each other and still feel part of a group; towards the end of the programme the group begins to separate and students gradually revert back to referring to themselves as 'I', rather than 'we'.

In relation to the possible limitations of this experiment, all focus groups relied on the views of a relatively small number of students. However, this was not due to low participation rates, but to the 
small size of the MSc programme. Notwithstanding this, a relatively high and increasing proportion of class members took part in the focus groups and the outcome suggests that all of the participants took the opportunity to share their views. A similar positive result despite the small sample sizes is discussed by Darlow et al. (2016) who use small focus groups for students' evaluation of interprofessional education programmes. Section 6.3 discusses possible ways to deal efficiently with larger cohorts of students.

\subsubsection{Report and Communicate Results of the Feedback}

During each focus group notes were collected and then reported to senior members of staff, typically the Head of School, the PAD, and the Director of Administration and Students' Affairs, and to the students. The aim was to review the answers, gather opinions from a larger number of 'stakeholders' of the programme, and disseminate the information. The results are most useful if they are "turned around quickly to the various stakeholders including the students" (Bohms, 2013).

After the February 2015 focus group, the report was sent to the students for a final check before sending it to more senior members of staff to make students take responsibility 'on their own words' outside the informal environment of the focus group. Notably, one of the students has reviewed and corrected some information that he gave during the focus group. Although the approach of seeking a second review is very useful, obtaining final confirmation and consent from the students is timeconsuming and generally requires sending two reminders. The risk is that the chain of communication can become quite elongated, while staff members' time is short and filled with multiple tasks.

In addition, the informality of the discussion needs to be translated into a more formal document and this can also be time and resource-intensive. One idea to alleviate the 'cost' of the process is to request one or two students to capture the discussion and then send their notes to the facilitator/evaluator and to the rest of the students. This can help strengthen the concept of students working together as partners with programme staff towards quality enhancement. After all, students are engaged in a process which aims at voicing their requests and ideas on how to enhance their learning experience. Therefore, it may prove useful to involve them also in the post-discussion stage.

It is also important for a correct interpretation of the results to share the report with senior staff and discuss with colleagues who have longer teaching experience. The results from the focus groups were also discussed with an experienced staff-member of the Centre for Quality Support and Development at the institution. Interpreting feedback from the students is an emotional business (Hendry, Peseta, \& Barrie, 2005). As Hounsell (2009) points out: "it is easy to fall into one of two traps: dismissing unwelcome feedback too readily, or dwelling gloomily on less favourable comment to the neglect of those features of teaching which have attracted praise." Asking for a "second opinion' can provide a helpful counterbalance.

\subsubsection{Take Actions}

Interpretation of the results needs to be followed by action. However, their interrelationship can be problematic. Taking action and implementing enhancements may require the support of more senior and experienced colleagues. There are multiple stakeholders in the feedback process: not only the students, the teaching staff, and the departmental management, but also the University International Office, the marketing and admission teams, and future potential students. Disseminating information to them can be useful; however, one has always to consider all issues related to confidentiality and ethical consent from the students must always be obtained. 
One positive example of larger involvement of stakeholders following a focus group is reflected in the focus group of February 2015. The group had evidenced a number of issues with some of the PhD-Teaching Assistants. This issue was reported to the PAD and the Head of School and it opened a debate concerning the use of PhD Teaching Assistants at School level including the way in which they were supported. The feedback from this focus group was the trigger for helpful wider discussion at a senior management level.

\subsubsection{Feedback to Students about the Actions (Closing the Feedback Loop)}

After consulting senior staff, it is important to respond to students over appropriate and achievable action to be taken. However, Hounsell (2009) clarifies that: "sometimes feedback produces unclear results which only further investigation might help to resolve, or it may be necessary to explore a variety of possible ways of both interpreting and responding to a given issue or difficulty." A response to students at the end of the feedback cycle "is especially important in that it will convey to students the sense that their feedback is valued by the institution as a whole".

Students were informed about the process that followed each focus group, i.e. the results were reported in a document, then passed to students for comments, and finally sent to senior staff. As an example, one email of the facilitator to the students explains: "I would ask please to each of you who participated today to send me a written consent to use the feedback (which is completely anonymized) to escalate some of the points raised to more senior members of staff." Finally, if any action is taken as a response to students' feedback, students must be informed promptly, so that they can appreciate the usefulness of their engagement in the feedback process.

\subsection{Lessons Learned from this Experience with Focus Groups}

As mentioned earlier, focus groups are not always adopted as a standard feature because they can be time and resource-intensive and because they may require specialist training of staff in order to be effective. There are also problems related to students' representativeness and participation. Ensuring participation can be easier in programmes involving a smaller number of students, as they can be reached more easily. However, the exchange of communications required to inform students, receive confirmations, set up and organize the meeting, and then communicate the results of the process, can be quite onerous. It is important for HE staff members and academics to have enough time, energy, and resources in order to continue being actively involved with students, fostering discussion and sharing views. Delegation of some tasks can be a viable solution to be explored.

First, it is important to look into the possibility of a closer involvement of specialized units, such as a Centre for Quality Support and Development, in helping out to collect the students' verbal feedback. It can be also useful to involve more administrative staff in practical aspects of the meetings' organization, such as sending out reminders to students, requesting confirmation of students' availability, booking rooms, etc. The verbal feedback process needs to be gradually 'institutionalized': it should not to be considered a one-off exercise run by a few committed individuals, but a recognised practice in place in each department. The expectations should be gradually moving towards an involvement of multiple parties into the process.

Second, the paperwork load should be effectively managed. Making use of recorded 'voice notes' and quick voice-reminders can help to obtain a faster and more efficient communication between all parties. Different pieces of feedback collected during the year will be then reported into a unique 
end-of-year report which reviews in details all necessary changes on the programme structure and organization. This report will be circulated among staff members, Faculty members, and senior management. Moreover, the ethical consent to use the confidential information should be requested right at the end of each meeting from the students, in order to avoid sending out many emails afterwards.

Third, it is helpful to draw on the support of elected Student Representatives, especially when focus groups are used to collect feedback from larger cohorts of students. The elected students can report to the focus group facilitator on any issue related to the meeting organization. The communication of practical information and the incidental feedback can be shared and collected more quickly with one person than with multiple people. However, it is important to make sure that the 'elected' person understands the importance of communicating and reporting to the rest of the students. A preliminary meeting with the student will help to clarify all aspects.

The verbal feedback from focus groups run with the help of the Student Representatives is however different from the typical Student-Staff Liaison Committees (SSLC). In the Business School considered in this study the elected Student Representatives participate in one formal SSLC meeting per term together with the Programme Directors and the Dean or Head of School. They receive specific training for this purpose. Nevertheless, SSLC meetings are not organised as focus groups. Also, while the elected students can be contacted by other students about requests to raise specific issues, they have no explicit responsibility or duty to carry out preliminary focus groups to agree the issues which need to be addressed in the SSLC meetings.

Wilson et al. (2015) provide instead an interesting example of focus groups for curriculum review where a number of students are elected as 'group leaders'. At the beginning of each academic year these student-leaders convene with the Dean to organize focus groups. They are provided written guidelines for proper interviewing techniques necessary for an objective focus group. They contact the students to explain the purpose of the focus group, remind students of the anonymity of their responses, and solicit participation. The group leaders also record all comments made during the focus group and later produce a formal written report which is then used in a meeting with the course director to explain the results of the focus group thoroughly and objectively, clarify any ambiguities, and highlight those messages which reflect the overwhelming majority of the student cohort. This method can help the course director to collect verbal feedback from focus groups in a less time- and resource-intensive manner; however, the efficacy of this solution lies in the level of commitment, training, ability and communication skills of the group leaders. ${ }^{4}$

Finally, ahead of the focus groups it is very important to build good awareness about cultural differences that can impact the effectiveness of the communication between the facilitator/s and the students and between the students themselves. After the focus group in February 2015, one of the students sent an email to apologise to have been too harsh in her comments. From the email, it seems the student had received some remarks from the rest of the group which felt her interventions too open and frank. The student received a long reassuring response from the PD. Interestingly, most of the students enrolled in the MSc IBIF come from Middle-Eastern countries. While Arabic speaking students typically have confidence in their spoken English skills and feel comfortable in informal listening and speaking situations, as explained in Table 1 in Appendix I, their culture is characterised by high-context communication style and awareness of power distance. The student was very active during the focus group and was using a direct explicit language, for example answering 'No' to a

\footnotetext{
${ }^{4}$ Hsih et al. (2015) describe a similar example of evaluation where feedback is collected via focus groups by student representatives and faculty members get involved only later in the process when they meet with the student representatives.
} 
question on whether she was satisfied or not by the available optional modules or 'I disagree' when one of the other students was asking for consensus from the rest of the group. In high-context communication styles a direct 'No' or 'I disagree' could be interpreted as signs of disrespect towards the higher 'authority', in this case the Programme Director, and the rest of the group. In this communication style, one has to convey the message diplomatically and consider the feelings of the listeners. In this case, however, the main listener ( $\mathrm{PD} /$ facilitator) had a different culture and communication style (Western style) where a direct explicit (low-context style) are the 'norms'.

This experience teaches two interesting lessons. First, a facilitator/evaluator has to consider whether the used language is 'acceptable', 'usual' and 'familiar' to students from different backgrounds. If the 'preferred institutional style' in a UK HEI is a direct, exacting, personal one, a facilitator should not assume that this is also the preferred style of the students who participate in the discussion. The student's concern about the harshness of her responses may be the effect of the cultural background of the group, perhaps emphasised by her gender, but it may also be a sign that the facilitator may have not completely reassured the group about the informality of the setting. There should be no post-discussion 'regret'.

Second, the activism and spontaneity of the focus group has succeeded in boosting confidence in the student and a sense of openness and frankness in the conversation, despite the cultural background of the group. For Business and Finance students this experience is even more important as it prepares them for team discussion where they need to express their opinions with confidence. This experience has demonstrated that students can become empowered when they are called to collaborate in the improvement of a 'service'. They can enjoy the sense of being equal partners in the conversation when the conversation is organized in such way to gain their 'trust'.

Learning more about the students surely helps in this sense. There are several occasions when Faculty and staff can learn more about students and most of them do not require any extra time. Informal conversations can be elicited at the University cafes and restaurants, while queuing for a coffee or having a meal, or when students are invited at receptions or at extra-curricular events. Creating opportunities to talk is one way to improve the multicultural communication. Another one is to keep up-to-date with the T\&L literature on how HEIs can improve communication in an intercultural setting.

\section{Concluding Remarks}

The lack of popularity of verbal informal feedback methodologies, such as focus groups, by HEIs is mainly due to their resource intensive nature, and to possible communication issues related to the international students' heterogeneity, particularly in Business Schools, and to differences in communication styles across cultures. The informal communication needs to translate into formal documents in order to disseminate the results and to take action: this can be another challenging aspect of the process. Finally, in the informal feedback process, the facilitator needs to be able to communicate effectively and to make students feel comfortable: at a managerial level it may not be easy to single out those staff members who may be more skilled in this job.

Despite all the 'costs', focus groups can be a rich source of information, in particular in the formative stages of a new programme in a HEI. However, as the realist evaluation approach 
explains, students' feedback should not be used in isolation. A programme is 'an open system' and students are only one, albeit the major, group of stakeholders.

The importance of the focus groups is not limited to the improvements of quality of teaching and learning, but it reverberates across the broader students' experience and to the nature of the studentteacher partnership. The following points represent benefits of feedback focus groups, which have been observed in this experience:

- By engaging in open-ended and probing discussion about their learning experience, the verbal feedback-process can help to develop higher-order thinking skills in international students.

- The verbal feedback process can provide international students with a toolkit to "negotiate their way" and make sure that diversity and full inclusion can become a central focus in their experience.

- $\quad$ The verbal feedback helps to achieve at the institutional level a closer connectedness with the students' international backgrounds and a fuller recognition of the differences.

- $\quad$ The process can represent one of the various ways a HEI can engage with students as partners in the learning process.

- $\quad$ Despite the verbal feedback process tending to be very informal, it can be channelled into a more systematic process.

- $\quad$ This process can take into account differences across cultures in the communication styles and in the perception of the relationship between educators and students.

- The informality of a verbal process does not rule out the application of general guidelines and procedures.

It is recommended that HEIs work on training to develop students' and staff's skills in order to achieve all positive results. Staff members need to be clear on the motives of the feedback and the potential benefits for students, in particular when the programme cohorts are characterized by multiculturalism. The cultural exchange that takes place in these informal discussions is an overarching aspect of the experience. 


\section{Bibliography}

Adams, M. J., \& Umbach, P. D. (2012). Nonresponse and online student evaluations of teaching: Understanding the influence of salience, fatigue, and academic environments. Research in Higher Education, 53(5), 576-591.

Bohms, E. (2013). Introduction. In H. Murray H., \& P. Smith (Eds.), Closing the Loop: Are Universities doing enough to act on student feedback from course evaluation surveys? Electric Paper Ltd. http://www.evasys.co.uk/news/newsreader/Closing-the-loop.html/ Accessed 19 June 2017

Biggs, J. (2001). The reflective institution: assuring and enhancing the quality of teaching and learning. Higher Education, 41(2), 221-238.

Bligh, D. (1998). What's the use of lectures. ( $5^{\text {th }}$ ed.). Exeter: Intellect.

Braddock, R., Roberts, P., Zheng, C., \& Guzman, T. (1995). Survey on skill development in intercultural teaching of international students, Macquarie University, Asia Pacific Research Institute.

Brandl, K., Mandel, J., \& Winegarden, B. (2017). Student evaluation team focus groups increase students' satisfaction with the overall course evaluation process. Medical Education, 51(2), 215-227.

Brennan J., \& Williams, R. (2004). Collecting and using student feedback: a guide to good practice. UK Higher Education Academy, Learning and Teaching Support Network. https://www.heacademy.ac.uk/system/files/id352_collecting_and_using_student_feedback_a_guide to good practice.pdf / Accessed 19 June 2017

Brookfield, S. D. (1995). Becoming a critically reflective teacher. Wiley: Jossey-Bass Higher and Adult Education Series.

Brown, P., \& Levinson, S. (1987). Politeness: Some universals in language usage. Cambridge: Cambridge University Press.

Bunce, L., Baird, A., \& Jones, S. E. (2016). The student-as-consumer approach in higher education and its effects on academic performance. Studies in Higher Education, 1-21.

Carroll, J. (2005). Strategies for becoming more explicit. In J. Carroll, \& J. Ryan (Eds.): Teaching international students - Improving learning for all. Oxon: Routledge.

Caruana, V., \& Oakey, D. (2004). Negotiating the boundaries of discipline: Interdisciplinary teaching and learning in the knowledge economy. Society for Research in Higher Education Annual Conference, University of Bristol.

Chang, J. (2001). Chinese Speakers. In M. Swan, \& B. Smith (Eds.): Learner English (pp.310-324). Cambridge: Cambridge University Press.

Chen, L. R. (1987). Assessing Asian language performance: Guidelines for evaluating limited English-proficient students. Rockville, MD: Aspen.

Cohen, L., Manion, L., \& Morrison, K. (2007). Research methods in education.(6th ed.). Routledge.

D'Andrea, V., \& Gosling, D. (2005). Improving teaching and learning in Higher Education: A whole institution approach. Maidenhead: Open University Press. 
Darlow, B., Donovan, S., Coleman, K., McKinlay, E., Beckingsale, L., Gallagher, P., Gray, B., Neser, H., Perry, M., \& Pullon, S. (2016). What makes an interprofessional education programme meaningful to students? Findings from focus group interviews with students based in New Zealand. Journal of Interprofessional Care, 30(3), 355-361.

Day, K., Grant, R., \& Hounsell, D. (1998). Reviewing your teaching. TLA Centre, University of Edinburgh/UCoSDA, Sheffield.

De Vita, G., \& Case, P. (2003). Rethinking the internationalisation agenda in UK higher education. Journal of Further and Higher Education, 27(4), 383-98.

EvaSys Enterprise Survey Management (2016) Achievability /Electric Paper Ltd [Computer software]. Retrieved from www.achievability.co.uk/evasys-survey-evaluation-software

Fairclough, N. (1989). Language and power. London: Longman.

Furneaux, C., Locke, C., Robinson, P., \& Tonkyn, A. (1991). Talking heads and shifting bottoms: The ethnography of academic seminars. In P. Adams, B. Heaton \& P. Howarth (Eds.): SocioCultural Issues in English for Academic Purposes. London: Macmillan - Developments in English language teaching Series.

Gibbs, A. (1997). Focus groups. Social Research Update, Issue 19.

http://sru.soc.surrey.ac.uk/SRU19.html / Accessed 19 June 2017

Gibbs, G., Habershaw, S., \& Habershaw, T. (1989). 53 Interesting ways to appraise your teaching. $\left(2^{\text {nd }}\right.$ ed.). Bristol: Technical \& Educational Services.

Goldfarb, S., \& Morrison, G. (2014). Continuous curricular feedback: A formative evaluation approach to curricular improvement. Academic Medicine, 89(2), 264-269.

Gudykunst, W. B., Ting-Toomey, S., \& Chua, E. (1988). Culture and interpersonal communication. Newbury Park, CA: Sage Publications.

Gudykunst, W. B., Ting-Toomey, S., \& Nishida T. (1996). Communication in personal relationships across cultures. Thousand Oaks, CA: Sage Publications.

Harrison, K., \& Clouder, D.L. (1998). Focus on quality, New Academic, 7(1), 11-14.

Hendry, G., Peseta, T., \& Barrie, S. (2005). How do we react to student feedbacks?, Synergy, 22, University of Sydney, Institute for Teaching and Learning.

Higher Education: Students at the heart of the system. (2011). UK Government, Department for Business Innovation \& Skills.

https://www.gov.uk/government/uploads/system/uploads/attachment data/file/32409/11-944-highereducation-students-at-heart-of-system.pdf/ Accessed 20 June 2017

Hofstede, G. (1997). Cultures and organization: Software of the mind. (1 ${ }^{\text {st }}$ ed.). McGraw-Hill USA.

Hounsell, D., Tait, H., \& Day, K. (1997). Feedback on courses and programmes of study: a handbook. University of Edinburgh, Centre for Teaching, Learning and Assessment.

Hounsell, D. (2009). Evaluating courses and teaching. In: H. Fry, H., S. Ketteridge, \& S. Marshall, (Eds.), A handbook for teaching and learning in higher education - Enhancing academic practice. ( $3^{\text {rd }}$ ed.). London: Routledge. 
Hsih, K.W., Iscoe, M.S., Lupton, J.R., Mains, T.E., Nayar, S.K., Orlando, M.S., Parzuchowski, A.S., Sabbagh, M.F., Schulz, J.C., Shenderov, K., \& Simkin, D.J. (2015). The student curriculum review team: How we catalyze curricular changes through a student-centered approach. Medical Teacher, 37(11), 1008-1012.

Jones, F. J. (1999). From silence to talk: Cross-cultural ideas on students' participation in academic group discussion. English for Specific Purposes, 18(3), 243-259.

Kandiko, C. B., \& Mawer, M. (2013). Student Expectations and Perceptions of Higher Education. QAA Report, London: King's College. https://www.kcl.ac.uk/study/learningteaching/kli/People/Research/DL/QAAReport.pdf / Accessed 23 July 2017

King, M., Morison, I., Reed, G., \& Stachow, G. (1999). Student feedback systems in the Business School: a departmental model. Quality Assurance in Education, 7(2), 90 - 100.

Koutsantoni, D. (2006). Internationalisation in the UK. In: Leadership Challenges of Globalisation and Internationalism Leadership Summit Report. http://www.lfhe.ac.uk/publications/reports.html / Accessed 19 June 2017

Lesnik-Oberstein, K. (2015). "Let UK Universities Do What They Do Best - Teaching and Research.” The Guardian, Letters, July 6. http://www.theguardian.com/education/2015/jul/06/let-ukuniversities-do-what-they-do-best-teaching-and-research/ Accessed 23 July 2017

MacKinnon, D., \& Manathunga, C. (2003). Going global with assessment: What to do when the dominant culture's literacy drives assessment. Higher Education Research and Development, 22(2), 131-144.

Marlina, R. (2009). "I don't talk or I decide not to talk? Is it my culture?" - International students' experiences of tutorial participation. International Journal of Educational Research, 48(4), 233-244.

May, T. (2011). Social research : issues, methods and process. ( $4^{\text {th }}$ ed.). Open University Press.

Munday, J. (2006). Identity in focus: The use of focus groups to study the construction of collective identity. Sociology, 40(1), 89-105.

Neuling, I. (1999). Differences in communication styles between cultures. Munich: GRIN Publishing GmbH. www.grin.com/en/e-book/104380/differences-in-communication-styles-between-cultures / Accessed 19 June 2017

Okabe, R. (1983). Cultural assumptions of East and West: Japan and the United States. In: W.B. Gudykunst (Ed.), Intercultural communication theory: current perspectives (pp. 21-41). Beverly Hills.

Pawson, R., \& Tilley, N. (1997). Realistic evaluation. London: Sage Publications.

Pawson, R., \& Tilley, N. (2004): Realist evaluation.

http://www.communitymatters.com.au/RE_chapter.pdf/ Accessed 20 June 2017

Phipps, A. M., \& Gonzalez, M. (2004). Modern Languages: Learning and Teaching in an Intercultural Field. London: Sage Publications. 
Robertson, R., Line, M., Jones, S., \& Thomas, S. (2000). International students, learning environments and perceptions: a case study using the Delphi technique. Higher Education Research \& Development, 19(1), 89-102.

Romaine, S. (1986). The language of children and adolescents: The acquisition of communicative competence. Oxford: Blackwell.

Securing a sustainable future for higher education: an independent review of higher education funding and student finance [Browne Review] (2010). UK Government, Department for Business Innovation \& Skills

https://www.gov.uk/government/uploads/system/uploads/attachment_data/file/422565/bis-10-1208securing-sustainable-higher-education-browne-report.pdf/ Accessed 20 June 2017

Smith, P., \& Morris, O. (2011). Effective Course Evaluation: The Future for Quality and Standards in Higher Education, Electric Paper Ltd.

http://www.lse.ac.uk/newsAndMedia/aroundLSE/archives/2011/effectiveEvaluationReport.pdf / Accessed 20 June 2017

Skype. (2014) Skype Technologies S.A. (Version 6.14.32.105) [Computer software]. Retrieved from https://www.skype.com/en/get-skype/

Smithson, J. (2008). Focus Groups. In P. Alasuutari, L. Bickman \& J. Brannen (Eds.): The SAGE Handbook of Social Research Methods (pp. 357-370). London: SAGE.

Snowden, C. (2013). Foreword. In H. Murray H., \& P. Smith (Eds.), Closing the Loop: Are Universities doing enough to act on student feedback from course evaluation surveys? Electric Paper Ltd. http://www.evasys.co.uk/news/newsreader/Closing-the-loop.html/ Accessed 19 June 2017

Thomas, L., MacMillan, J., McColl, E., Hale, C., \& Bond, S. (1995). Comparison of focus group and individual interview methodology in examining patient satisfaction with nursing care. Social Sciences in Health, 1(4), 206-220.

Tomlinson, M. (2014). Exploring the Impacts of Policy Changes on Student Attitudes to Learning. The Higher Education

Academy. https://www.heacademy.ac.uk/system/files/resources/exploring_the_impact_of_policy_c hanges_student_experience.pdf/ Accessed 23 July 2017

Tomlinson, M. (2017). Student perceptions of themselves as 'consumers' of higher education. British Journal of Sociology of Education, 38(4), 450-467.

Wilson, M. W., Morreale, M. K., Waineo, E., \& Balon, R. (2013). The focus group: a method for curricular review. Academic Psychiatry, 37(4), 281. 


\section{Appendix I}

\section{TABLE 1: DIFFERENT COMMUNICATION STYLES IN DIFFERENT CULTURES}

\begin{tabular}{|c|c|}
\hline DIRECT STYLE & $\begin{array}{l}\text { A speaker expresses his/her true intentions in terms of his/her needs and desires. The language is used in a straightforwarc } \\
\text { and precise way (Gudykunst, Ting-Toomey, \& Nishida, 1996). Categorical words, such as "absolutely" and "certainly", ar } \\
\text { often employed as well as "no" in order to answer in the negative. Members of individualistic, low-context cultures tend to } \\
\text { use the direct style. According to Hofstede's theory, the low-context communication is one "in which the mass of the } \\
\text { information is vested in the explicit code" (Hofstede, 1997). The receiver does not have to take a complex context into } \\
\text { consideration, when decoding the message: what must be said, will be said. }\end{array}$ \\
\hline INDIRECT STYLE & $\begin{array}{l}\text { A speaker uses imprecise and even ambiguous words to communicate the message. Words like "maybe" or "perhaps" are } \\
\text { employed and a direct "no" is avoided in order not to hurt the feelings of other in-group members and "to preserve the } \\
\text { group harmony and conformity" (Gudykunst et al., 1996). Members of collectivistic, high-context cultures prefer to use the } \\
\text { indirect verbal style. }\end{array}$ \\
\hline EXACTING STYLE & $\begin{array}{l}\text { The speaker just uses those words which describe exactly his/her intention. No additional words or paraphrases are } \\
\text { required. This style can be found in low-context cultures which are low to moderate on Hofstede's uncertainty avoidance } \\
\text { dimension (mainly North American and North European cultures). }\end{array}$ \\
\hline
\end{tabular}


CONTEXTUAL STYLE

INSTRUMENTAL STYLE

AFFECTIVE STYLE
It varies depending on the status of the interlocutors. It is mostly used by members of collectivistic, high-context cultures. It is goal-oriented and employs a sender-oriented language. The speaker tries to persuade the listener in a confrontational setting. This style is dominant in individualistic, low-context cultures.

It uses a receiver-oriented language. The speaker is not only expected to transmit his/her message, but at the same time to be "considerate about other's feelings" (Okabe, 1983), paying much attention to the listener's reactions and adjusting to it. The listener is supposed to "catch on quickly" the speaker's message, before the speaker must pronounce his/her intentions clearly or logically. 


\section{Appendix II}

TWO EXAMPLES OF FOCUS GROUPS' QUESTIONS AND ANSWERS (REPORTS)

\section{Focus group on Programme Evaluation: Report}

\section{MSc Investment Banking and Islamic Finance (12 months programme)}

$17^{\text {th }}$ July $2014-$ Skype Call

\section{Attendees:}

- Programme Director - MSc Investment Banking and Islamic Finance; also Personal Tutor for all students in the programme

- Five students from MSc IBIF - 12 months programme (in this report students are kept anonymous)

Below I report the questions asked to the students and their answers.

1) What attracted you to our institution? Why did you choose this programme?

The students agree that their main driver was a keen interest in Islamic Finance and the unique mix of Islamic Finance and Investment Banking that our MSc programme offers. They also acknowledge that they were attracted by our institution because of its high position in the ranking for Finance programmes (in particular they mention The Guardian ranking), as well as for the location (very close to London). Most students have been sponsored by their employers and Governments that requested them to enrol in a very serious programme delivered by a well-reputed institution. One student from Saudi Arabia tells us that he is working towards having our institution officially included in the Government list of "trustable" institutions to be recommended to the Saudi students willing to study in the UK. His main reason for doing that is his personal great experience. Finally, all students agree that the UK is still the preferred country for Postgraduate education in the Middle East, given the proximity to their home-countries.

2) Having had the chance to see how this programme compares with the others we offer; do you still feel this was the right choice?

The students say that the programme was the right one for them given their interest in Islamic Finance. They also say that they are very satisfied for having chosen the 12-months version of this MSc programme as the study-abroad period has added up much to their knowledge and personal experience.

3) As you know, we have group projects and multiple-choice exams as methods of assessment for all our MSc modules in Part 1. What is your opinion about this kind of assessments? Did you experience any particular difficulty?

The students think that the tight time-constraints were the hardest challenge throughout the programme; however, they also admit that this is a specific feature of all MSc programmes in general. Students are happy for the mix of coursework, projects and final exams. They also did not express any concern on the multiple-choice exams. 
We have discussed the case of the withdrawal request from one student in the MSc IBIF, due to his lack of quantitative skills needed for the programme.

The students attending this focus group had no problems with quantitative subjects; however, they point out that the MSc programme website is misleading in this regard. The webpage that describes the requirements for the MSc Investment Banking and Islamic Finance says that students can apply for the programme also if coming from any other discipline and that there is "no quantitative requirement". [Direct action: I have doublechecked this information and this is indeed mentioned in our website. I have then suggested removing this line, as some quantitative skills are required in any basic Finance-related programme].

4) Was the programme well-structured?

Students appreciate that there are differences in the ways of lecturing and assessing between our institution and our partner institution in Kuala Lumpur. I have tried to investigate further, but students reassure me that they have found both equally good in different ways and styles.

They are happy about the programme structure, but suggest that the Part 1 Islamic Finance course should run in October, rather than in November [Direct action: this suggestion has been already taken into account and I have requested this change in the programme structure.] Students also think that this particular module is very dense and should be given 20 credits instead of 10. Finally, they discuss the problems they had last October when they were asked to prepare a research outline for their research projects in Islamic Finance. They had in fact no previous knowledge of the subject and only started their Islamic Finance lectures in November. [As mentioned earlier, this has been taken into account; moreover, the research projects have now been made optional to all students in MSc IBIF and no more compulsory for the 9-months students].

5) Did you take any module that was taught in blocks, and if so did you feel this worked well?

Students think that lectures and seminars for all Islamic Finance courses were too concentrated at our institution. Students say they did not have the necessary time between lectures and seminars to re-think the topics of the lectures and make use of them profitably in the seminar. [This is an issue we should take into account: students think it would be enough to have at least lectures on one day and seminars the day after, rather than having them all in the same day.] Students do not think they had any problem with teaching in the time they have spent at our partner institution.

6) Which types of assessment did you find most useful and most challenging?

Students explain that a mix of assignments and exams is their preferred assessment type. Students reflect on the differences between the Islamic Finance teaching in our institution and in our partner institution.

At our institution:

The level of the lectures and lecturers is very high. Students attend theory-based lectures that foster a lot of critical thinking in Islamic Finance as a key area of business, but also as a rather "undeveloped area" which needs a lot of improvement. They enjoyed this critical 
assessment of the discipline. They think that the teaching level is much higher than a basic introductory level to Islamic Finance. They clarify they do not want the teaching level to be more basic, but they would prefer to be told which basic resources to refer to (for instance an Islamic Finance textbook), rather than browsing them on the Internet under the risk of finding scarce, incomplete or wrong type of information. Students have expressed this point to their Islamic Finance lecturers who told them that referring to one textbook for this area might not be a good idea, while it is better to read updated resources, such as journal articles which were given to them. Students would still prefer to have clearer guidance on which resources they need to read in order to acquire a complete basic knowledge of the subject and then integrate them with the more advanced level of their lectures.

At our partner institution:

After the experience at our institution and the knowledge acquired there, students have found the teaching level in Malaysia more basic and in some points a little repetitive. They remark also a difference in the approaches. At the partner institution Islamic Finance is taught as "the best way", and this is in sharp contrast with the critical approach at our institution. However, students think that the mix of the two approaches makes a great learning experience. In the UK students were able to apply critical filters to their learning experience and enhanced it. Meanwhile, they had the opportunity to engage with lecturers who have a different background and spend time in a country where Islamic Finance is the way of doing Finance. They are a bit disappointed however for the lack of opportunities to meet many practitioners.

\section{7) Which types of feedback (oral/written/individual/group) were most useful?}

Students agree that written feedbacks are very helpful. Students tell me that one lecturer was very delayed with his feedback for one of the assignments; students say they would have preferred to receive this feedback earlier on.

8) Did you feel you had a good choice of optional modules? If not, why?

Students feel they had limited choice and would have preferred to have a larger pool of optional modules [This suggestion has been taken promptly on board and now student in MSc IBIF programme have been granted a larger number of optional courses].

9) Are there any subjects which you felt were missing from the programme?

Students are happy with the current subjects and have no major comment. They only think that the topic of Islamic Law and Shari'a regulation should be a little expanded (in a lay approach, without any religious element included).

10) Did you feel able to contact staff members with questions academic/administrative/personal problems?

Excellent comments: students have not faced any problems in both HEIs. 
11) Do you think you had fairly good opportunities to meet practitioners?

Students say that at our institution several interesting events were organized by the PD, but they suggest managing their timings, so not to have these events overlapping with exams and revision (or vacation) time.

Students are a bit disappointed on this point by the partner institution. They were "promised" a visit to the stock and commodity exchanges which never really happened. In one occasion one of the lecturers seems not to have shown up in one extra-curricular activity [I could not understand much about this point and the students were very vague.] On the other hand, they had one more opportunity to meet an influential Islamic Finance practitioner (for a dinner) and were positively impressed. They think it was a very rewarding experience.

12) Did you feel able to raise issues through the staff-student committee?

Students say they had no substantial issue to rise. Small problems were "internally" addressed to and handled by the PD.

13) Would you recommend this programme to others?

Not only students would recommend it in the future, but they have already recommended it to their fellow colleagues and to several friends back home who are interested in pursuing a Postgraduate education in Finance.

14) Would you be prepared to help our institution to promote this programme in your region? Is yes, what would your ideas be in this respect?

Students would be happy to support us in future recruitment activities. Some valid ideas were also mentioned. (See at point 1 the comment on the Saudi Arabian Government's list of recommended institutions).

15) Other programme-specific issues.

None mentioned. 


\section{Focus group on Programme Evaluation: Report}

\section{MSc Investment Banking and Islamic Finance (9 and 12 months)}

\section{Spring Term - $6^{\mathrm{h}}$ February 2015 - ICMA Centre}

Attendees:

- Programme Director - MSc Investment Banking and Islamic Finance; also Personal Tutor for all students in the programme

- Eight students from MSc IBIF - 12 and 9 months programme (in this report students are kept anonymous)

\section{1) What attracted you to our institution? Why did you choose this programme?}

Three students indicate the combination of conventional and Islamic finance as one of the most attractive aspects of the MSc programme. The rest of the students seem to agree on this point. One student says that the programme appears to be one of the best Islamic Finance programmes available in the UK. Islamic Finance is a discipline taught appropriately only in a handful of countries. Access to the UK education system is another unique advantage of the programme that attracted students. One student asserts that our MSc IBIF is the best option amongst other programmes available in the UK. One student considers the MSc IBIF also a convenient option to access Islamic Finance expertise and knowledge in Malaysia, without the need of opting for studying any programme in that country. The students seem to appreciate also the fact that our programme is more focussed on Finance, rather than Law.

2) Having had the chance to see how this programme compares with other MSc programmes in Islamic Finance, do you feel this was the right choice? Why?

During our discussion, students drew several examples of differences between our MSc IBIF and the MSc in Islamic Finance in Durham University. They think the former is more quantitative and Finance-based, while the latter is more grounded into Law and Business. Students still prefer our programme over the other one, after careful consideration. They also appreciate the reputation of our institution, the facilities offered by our Centre (access to Thomson Reuters, Bloomberg, trading simulations, etc.). Two students report also that the admission criteria for our programme have lower demand in terms of quantitative skills, which makes this programme more accessible than the one offered by Durham University.

3) How do you evaluate so far: i) the overall quality of teaching from lecturers; ii) the overall quality of teaching from tutors; and iii) the variety of teaching methods and styles?

Students are not particularly satisfied with most of the teaching assistants in Part 1 Modules' seminars. They find some seminars not very useful: some of the teaching assistants were not re-connecting the seminars to the material of the lectures, as well as to the exam "techniques". Most of the students feel that some TAs have not added much to their understanding of the subject and they did not show to be very pro-active when enquired on topics which were not closely related to the questions in hand during the seminar. Examples of a pro-active attitude provided by the students are: a proposal to escalate a question to the lecturer, commitment to review some more material and offer an answer on Blackboard or in the next seminar, showing a confident attitude towards solving a problem. One student 
admits to have skipped several seminars as "they were not useful for the preparation to the exams". Another student thinks that as the TAs are PhD students who themselves have concluded their MSc programmes only short time ago, the expectations on their preparation should not be too high; nevertheless, the TAs should be more involved and interactive. Students feel also that the seminars should be more focussed on the exams' techniques, for example they would prefer to solve the exercises "by hand" rather than been shown how to execute them in Excel (as the software cannot be used during exams). Regarding the lecturers, students are overall satisfied.

\section{4) Do you feel you receive enough guidance and support from the teaching staff?}

No problems were raised on this point. Students say that all teaching staff responds to emails and Blackboard enquiries timely, and that all teaching staff is readily available to help during the office hours.

5) Are the recommended resources (textbooks, journal and newspaper articles, data, etc.) easily accessible via the library and the other teaching and learning facilities of the Centre and of the University (financial databases, literature databases, etc.)?

While textbook material is distributed for Part 1 Modules, the situation changes in Part 2. Students do not require to be given the material for all courses, but enquire on whether they should receive or not the textbooks for the compulsory modules (e.g. Corporate Finance). Students admit that the provision of lecture notes is helpful; however, those who are attending the module of Topics of Financial Regulation lamented lack of provision of readings and notes before the lectures. Some problems are also flagged in relation to the module Design, Implementation \& Risk Aspects of Islamic Financial Products \& Services. For this subject students are not given a recommended textbook (they admit to understand the reasons behind that: no very good textbook are available at a PG level). Nevertheless, they say that being given only lecture notes (besides, hardly readable because too small) make them feel unsure about: i) which resources to use for more detailed information; ii) how to prepare to answer essay-type questions in the exam. There are mixed feelings about this point: some students admit that the level of the Islamic Finance teaching is very advanced in the Spring Term and they need to make also a greater effort to fulfil the PG learning requirements. Students think that, despite the challenge, the lectures are very interesting. However, they would prefer to be given textual lecture notes (as done by the lecturer of "Principles of Islamic Commercial Jurisprudence" in Part 1), rather than in the form of slides with bullet-points.

6) For all the MSc common modules in Part 1 you are assessed via group projects and multiple-choice exams. What is your opinion about this kind of assessments? Did you experience any particular difficulty?

Students are overall satisfied by the mix of group projects and MCQs exams. Some are even quite enthusiastic. One student has offered some criticism on problems faced during the group project. The main problem is related to free-riders and inactive group members. The student proposes the use of peer-review evaluation forms (that can help students to flag these situations in less extreme circumstances more appropriately). The student also suggest that, when and if a particular situation is flagged to the lecturers, lecturers should then feed-back the students on the result of their action (not in terms of the decision on penalties, but in 
terms of re-assurance that the situation has been handled according to the University policy). This can boost students' confidence that their voices are effectively heard.

7) Which types of assessment did you find most useful and most challenging so far?

See reply above. In addition to the points raised above, one student complained about the exam timetable and the fact that two January Part 1 exams were only 6 hours apart. [However, the student has corrected his information after reviewing this report].

8) Do you think that the MSc IBIF programme is well-structured?

Students are satisfied with the overall structure, but rather unhappy to have most of the Islamic Finance modules concentrated in few weeks. They feel a need to "digest" better the topics from one lecture to the next one, especially when the material in hand is quite advanced. They think that the University might face a trade-off in terms of resources and lecturers available for such small group of students. Nevertheless, they fear that the clustering of lectures can have an impact on their learning ability.

9) Did you take any module that was taught intensively, and, if so, do you feel this works well?

See reply above.

10) Do you think you had a good range of optional modules made available for MSc IBIF?

Only one student feels a little unsatisfied, while the rest of the students are very happy with the large set of optional modules provided. The dis-satisfied student complains about the lack of variety in the 20-credits optional modules offered. A 9-months MSc IBIF student needs to make up 40 credits of optional modules: he/she may end up picking a large number of 10-credit modules to make up the required amount of credits. Another student raises the matter of accessing more specialist modules in conventional banking (such as Merger and Acquisition); however, the student admits that these modules could be specialist modules targeted to other MSc Programmes.

11) Do you feel able to contact staff members with questions on academic/administrative/personal problems?

Time was short to discuss this point appropriately, but students have not flagged any particular problem in their experience.

12) So far, would you recommend this programme to others?

Students feel very positive about it.

13) Other programme-specific issues.

None. 